\title{
Modern Risk Management Practices in the Companies of Housing and Utilities Infrastructure
}

\author{
Roman Gorshkov ${ }^{1, *}$ and Viktor Epifanov ${ }^{2}$ \\ ${ }^{1}$ Moscow State University of Civil Engineering, Yaroslavskoe shosse, 26, Moscow, 129337, Russia \\ ${ }^{2}$ National Research University Moscow Power Engineering Institute, 14, Krasnokazarmennayast., \\ Moscow, 111250, Russia
}

\begin{abstract}
Results of research in the field of risk management in the course of activities of the companies of housing and utilities infrastructure are presented in this article. Comparative analysis of the risk management paradigms was performed and risk formation factors were analyzed and considered, also there were educed the main problems of their assessment, which are accompanied with solution of the formation of mathematical apparatus tasks and methodology of the risks identification, the concept of integrated risk management in the form of a closed cycle including 4 trial functions is presented.
\end{abstract}

\section{Introduction}

The main purpose of integrated risk management is to find an optimal balance between risk and company-wide profitability. Combined or integrated bankruptcy risk, which can be determined by the manifestation of one or more of the listed above risks is the object of analysis and management as part of corporate risk management. Quantitative measure of "integrated" risk is usually volatility of market value of the company, for assessment of which standard deviation of return on equity is used (if they are traded in the stock market) or the standard deviation of the return on assets.

Everybody interested eventually in the risk of bankruptcy and its consequence, they are owners, managing directors, clients, creditors and the state represented by the controlling elements. In the financial sector, this interest is particularly undivertedas banks and investment companies nearly the most "opaque", and therefore risky investment objects for private investors. Any visible increase of bankruptcy risk is perceived by such investors as the signal of the almost immediate sale of shares belonging to them. Such management of integral risk of bankruptcy of the company, maintaining of the company on the level accepted for all interested parties are extremely important for the banking sector [1].

In practice, this shared purpose of strategic management of the company is achieved by definition of the optimal match between the size of attracted share capital and taken risks. Corporate risk management allows to solve this problem on the basis of the so-called

${ }^{*}$ Corresponding author: grk54@,mail.ru 
"portfolio approach", which considers company as a set of interrelated business lines characterized by different ratios of expected profitability and risk. Respectively, for securing of the same level of susceptibility to risk for every department the size of the capital has to be defined, and on the basis of this definition must be calculated summed demand of the company for the capital, taking into account internal effects of diversification. Portfolio approach gives a possibility to apply proven models of diversification of the investment portfolio to allocate capital on activities with the purpose of achievement of the required company-wide ratio "profitability/risk» [2].

\section{Methods}

The main principle underlying the complex risk assessment on the basis of unified and consistent approach in the decision-making process in three main spheres of the corporate management:

1. strategic planning (entrance and escaping of branch, expansion / reduction of presence in the market, individual share in investment projects etc.);

2. pricing of financial services and tools;

3. assessment of the results of the functional units heads and senior management of the company activities.

Successful implementation of the concept of integrated risk management is possible only with the interaction of three key components:

4. supervising;

5.methodological support;

6.information and analytical systems.

Basic functions of company-wide risk management can be visually presented in the form of the closed cycle "risk management wheel" (fig. 1.).

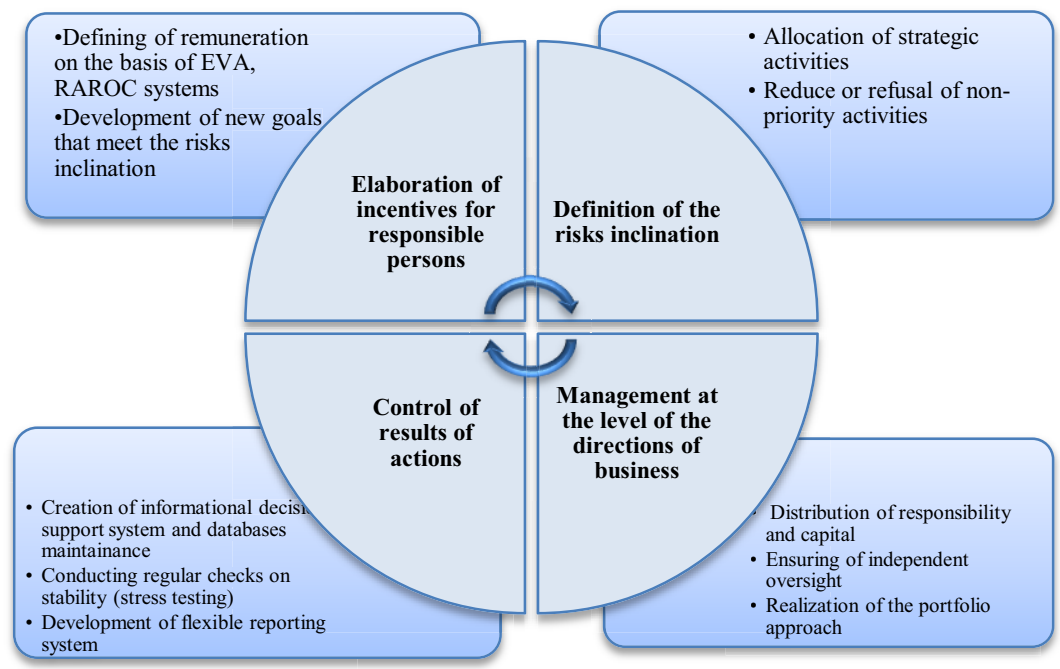

Fig1. Wheel of the risk management.

As appears from the picture, risk management of the company includes four main functions:

1. definition of the inclination to risk and choice of the "risk profile" (strategy) of the company according to the activity and geographic regions;

2. management of the risk profile at the level of individual activities; 
3. creation of the information decision support system (SPPR) for senior and middle management, allowing to monitor progress of the activity and valuate its results;

4. implementation of the system of the performance measurement of the activity results of responsibilities, which could create effective incentives to refusal from unacceptable and non-profitable risk.

Risk management process begins with defining the relationship of the company to the risk, or, as it is often called, "propensity to risk (risk tolerance, risk appetite). In practice this notion has rather descriptive, qualitative, than quantitative sense and therefore it can be interpreted in different ways from the direct formulation in the form of the mission of the firm which expresses its attitude toward the risk in a quantitative way [3], to the listing of desirable and non-desirable spheres of activities in a comprehension of the concrete company.

So, all of the specialized financial intermediaries can be positioned by their criteria of propensity to risk in the relative axis, extreme positions of which are occupied by the most risky (i.e. hedge funds) and the most conservative institutions (pension and insurance funds) respectively. The characteristic of the regarded company as "inclined" to risk or "avoiding" risk depends on which of these two "poles" its objectively gravitated by the property of the performed operations [4].

Table 1. Comparative analysis of the risk management paradigms

\begin{tabular}{|c|c|c|}
\hline $\begin{array}{c}\text { Basic } \\
\text { principles of } \\
\text { management }\end{array}$ & Existing paradigm & Necessary paradigm \\
\hline Consistency & $\begin{array}{l}\text { Fragmented risk } \\
\text { management } \\
\text { Management entity } \\
\text { separate independent } \\
\text { structural subdivisions of } \\
\text { companies } \\
\text { Subject to management } \\
\text { separated private risks in } \\
\text { line with functional units }\end{array}$ & $\begin{array}{l}\text { Integrated risk management, risk management of } \\
\text { the company } \\
\text { Management entity control subsystem. Risk } \\
\text { management should be coordinated and } \\
\text { implemented by the senior management and to be } \\
\text { performed by experts and managers within the } \\
\text { functional duties } \\
\text { Subject to management system of private and } \\
\text { integral risks }\end{array}$ \\
\hline Continuity & $\begin{array}{l}\text { Occasional management } \\
\text { Risk management is } \\
\text { performed as and when } \\
\text { necessary when managers } \\
\text { consider it necessary } \\
\end{array}$ & $\begin{array}{l}\text { Ongoing management } \\
\text { Risk management should be a continuous and } \\
\text { implemented at all levels of management, should } \\
\text { be objective and not depend on the wishes of } \\
\text { managers }\end{array}$ \\
\hline Complexity & $\begin{array}{l}\text { Limited risk-management } \\
\text { Risk management affects } \\
\text { individual risks, first of all } \\
\text { insured, investment and } \\
\text { separate financial risks } \\
\end{array}$ & $\begin{array}{l}\text { Advanced, complex risk management } \\
\text { Assessment and management of external and } \\
\text { internal risks inclusive of revealed interrelations, } \\
\text { interdependence of personal (native) and } \\
\text { integrated risks, synergy of the risks }\end{array}$ \\
\hline Motivation & $\begin{array}{l}\text { Purposeless (partially } \\
\text { targeted) management } \\
\text { Risk management is } \\
\text { performed without setting } \\
\text { of clear objectives, the risk } \\
\text { management strategy is } \\
\text { absent }\end{array}$ & $\begin{array}{l}\text { Stable management } \\
\text { Clear definition of the objectives of the risk } \\
\text { management, interdependent with the definition } \\
\text { of the company goal-setting } \\
\text { Risk management strategy must become a } \\
\text { component of the strategy of the company }\end{array}$ \\
\hline
\end{tabular}

Requirement for effective risk management of the company is the estimation or measurement of risks, at that the crucial component of functioning is accurate assessment of the level of risk. The issue of risk assessment involves two following tasks [5]: 
1) development of methodological bases of risk evaluation based on the proposed definition of risks and formulated basic principles according to which the risk assessment should be both invariant and variant and, from the assessment position, risk should be interesting not so much by itself, but by its impact on the financial results of the activity of the company;

2) formation of the mathematical apparatus of risk assessment, including:

- tools on application of methods and models of risks assessment, which designed as tables of applicability of methods of assessment of risks with consideration of the characteristics of different types of native and integral risks;

- tools of qualitative and quantitative risk assessment, monitoring and the establishment of borders and areas of the acceptability of risks in the capacity of which there were developed a matrix of qualitative assessment of risk level and ranges of quantitative values of the risks characteristics and a card of the risk tolerance;

- selection and application of computer models and software products, which are used for assessment and decision-making on risk management. Risk management methodology is presented on the fig. $2[6]$.

\section{Results}

Decision maker can analyze uncertainty associated with each of the elements of the system at the time of the economic risk analysis by separating treated system or economic process on the subsystem using mathematical methods, models and techniques, expertise and professional experience, computing. Degree of dependence between risk and components of this object can be considered. Cumulative impact of the risks subsystems on the process can be evaluated.

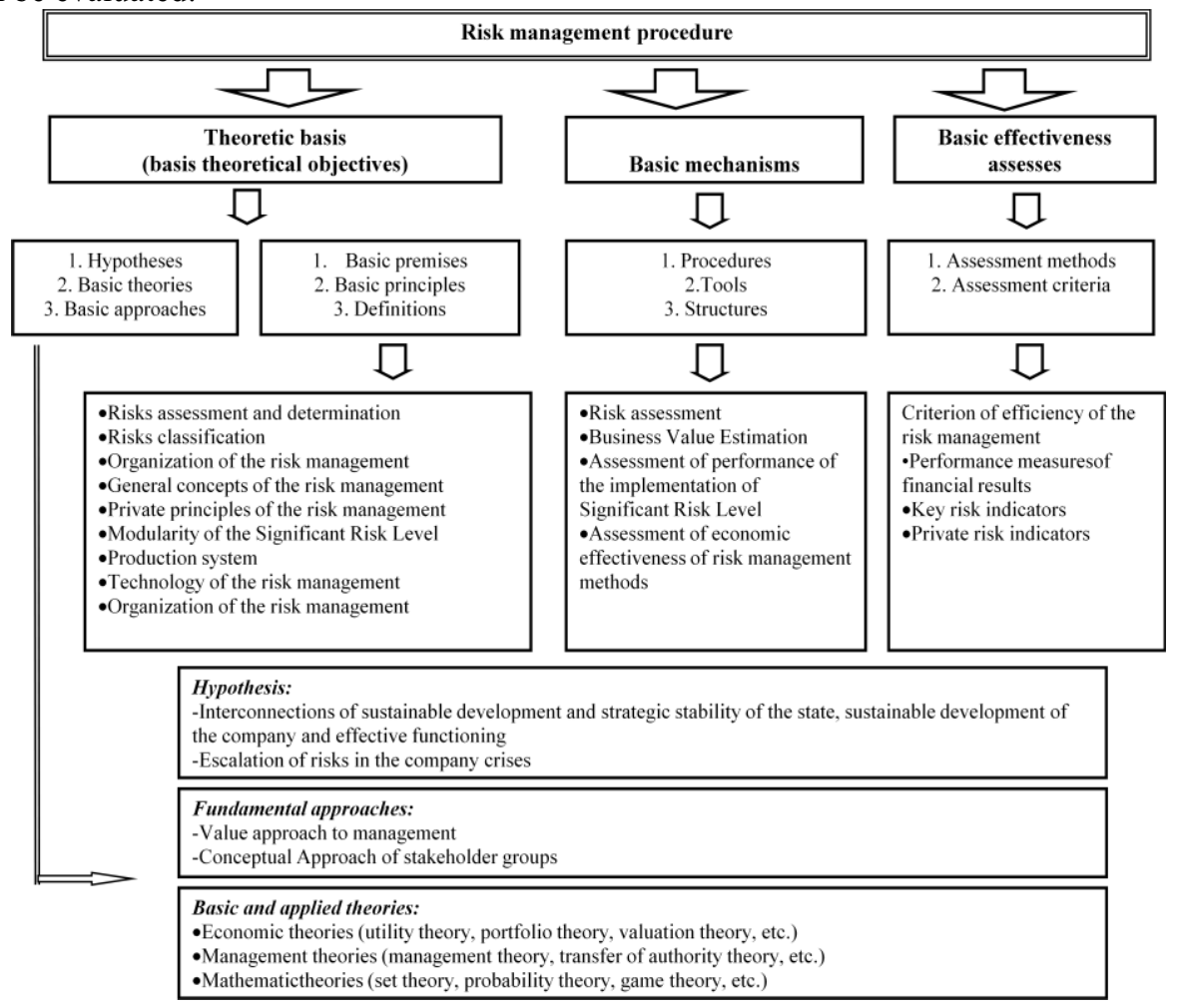

Fig. 2. Risk management methodology 
As a result of the risk analysis realization, a picture of possible risk events, the probability of their occurrence and consequences is produced. Strategy of management of risk and on this basis, the basis of the measures of prevention and decrease of risk is developed after comparison of the received values of risks with maximum-permissible [7].

Decision on degree of sufficiency of the planned measures must be accepted after selection of particular set of measures for elimination and minimization of risk. Realization of the project performs in case of sufficiency (taking the remainder of the risk), otherwise it is advisable to abandon the project (and avoid the risk).

The main values of economic risk assessment associated with winning or losing, the loss or profit as a result of economic or entrepreneurial activity. It is possible to assume that the theoretical way of economic assessment of risk is based on two parameters: the amount and probability of possible losses, and that means necessity of definition of the quantity of both characteristics after which risks become comparable against each other [8].

\section{Discussions}

The role of the quantitative assessment of economic risk increases significantly when there is a choice of alternate decisions of the optimal solution providing the greatest probability of the best result at the least expenses and losses according to problems of minimization and risk programming. Here it is necessary to identify, quantify, evaluate and compare elements of the considered economic processes, identify and define interconnections, trends, patterns, which describe them in the system of economic indicators, which is unthinkable without usage of statistical and mathematical methods and models in the economic analysis.

Economic-mathematical methods application allows to perform qualitative and quantitative analysis of economic events, to give the quantitative assessment of value of risk and market uncertainty and to choose the most efficient (optimal) decision. Mathematical methods and models allow to imitate different business situations and assess the consequences at the decision making, dispensewith expensive experiments.

Methods of economic-mathematical analysis, as a regulator of economic activity in the unity of internal and external uncertainties, providing the choice of optimal solutions, allow to analyze, measure and mathematically assess, measure the value and probabilities of minimization and programming of the risk with purpose of the best risk management on the basis of improved efficiency and quality of economic activity, uncertainty reduction. Risk category is probabilistic, so in the process of uncertainty assessing and quantifying risk characterization, the probabilistic calculations are used.

\section{Conclusion}

Quantitative assessment of probability of approach of separate risks and what they can do allows the decision-maker to allocate the most probable on emergence and influential in size risks which will be the objects for the further analysis for the decision making on expediency of implementation of the project. Assessment of the probability also helps to understand the capabilities of selective research and forecast of future actions. Applicable to the economic issues statistical methods are reduced to the systematization, processing and use of statistical data for scientific and practical conclusions. Method of the research based on the consideration of statistical data about one or another collection of objects, called statistics.

Methods of decision making in the conditions of risk are also developed and settled within the theory of statistical decisions. As already pointed out, essence of statistical 
method is that the statistics of the losses and profits taking place at this or similar company (economic situation) is analyzed and the magnitude and frequency of a particular economic result is established and the most probable forecast for the future is formed. The disadvantage of the statistical approach to the measurement of the risk is that it's based on available statistical data of past periods, while the risk assessment related to the future events. That reduces the value of this approach in the rapidly changing economic environment. At the same time, the advantage of this approach to the risk measuring is its objectivity.

\section{References}

1. J. Monahan, J.C. Energy and Buildings, 43(1), 1-188 (2011)

2. V.S. Kanhva, B.L. Efremyan, Nauchnoe obozrenie, 12, 295-298, (2016)

3. C.J. Adcock, N. Meade. European Journal of Operational Research,259(2), 746-765 (2017)

4. C. Furlong, S. De Silva, K.Gan, L. Guthrie, R.Considine. Journal of Environmental Management,191, 83-95 (2017)

5. K.Anagnostis, K.Alexios, Procedia Economics and Finance, 9, 120-132 (2014)

6. L. Shan, A. Yu, Y.Wu. Habitat International, 59, 90-100 (2017)

7. E.M. Kiseleva, M.L. Nekrasova, M.A. Mayorova, M.N. Rudenko, V.S Kankhva, International Review of Management and Marketing. 6, 95 (2016)

8. S.S. Uvarova, V.S. Kanhva, Y.A. Rogacheva,Vestnik MGSU, 6, 90-100(2016) 